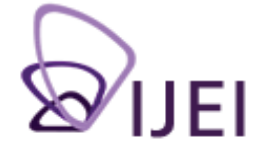

International Journal for Educational Integrity

\title{
An examination of factors related to plagiarism and a five-year follow-up of plagiarism at an Australian university
}

\author{
Guy J. Curtis \\ Murdoch University \\ g.curtis@murdoch.edu.au \\ Razma Popal \\ University of Western Sydney \\ razma85@hotmail.com
}

Keywords: plagiarism, understanding, seriousness, pressure, competitiveness, grades, longitudinal

\begin{abstract}
In this paper we report the results of a survey of student plagiarism carried out at the University of Western Sydney (UWS). This survey examined rates of plagiarism, understanding of plagiarism, perceived seriousness of plagiarism, and factors thought to be related to plagiarism such as the pressure students place on themselves to achieve high grades. Students who achieved higher grades plagiarised less than students who had lower grades. Perceived seriousness of plagiarism, students' competitiveness, and students' self-imposed pressure to achieve high grades were correlated negatively with incidence of plagiarism. Perceived seriousness of plagiarism mediated the relationship between self-imposed pressure to achieve good grades and rates of plagiarism. The data from the present survey (conducted in 2009) were compared with data from comparable students who completed the same survey at UWS five years earlier (2004). The comparison between the 2009 and 2004 data suggested a reduction in prevalence of plagiarism and an increase in both understanding and perceived seriousness of plagiarism between 2004 and 2009. We suggest that plagiarism may be reduced by means of educational programs that promote the perception of plagiarism as a serious academic integrity issue.
\end{abstract}

\section{Factors related to student plagiarism}

There is little doubt that plagiarism occurs among university students (Bennett, 2005). However, understanding why plagiarism occurs is perhaps more important than the knowledge that plagiarism occurs. Developing an understanding of the causes of plagiarism can give academics and university administrators helpful guidance as to how it may be reduced. There have been many studies inquiring into the reasons why students plagiarise and the reasons for plagiarism that these studies have discovered are many and varied. Some of the reasons students plagiarise include inexperience (Landau, Druen, \& Arcuri, 2002), immaturity (Deikhoff et al., 1996), differences in cultural practices (Zobel \& Hamilton, 2002), and personality (de Bruin \& Rudnick, 2007). However, there are some contradictory findings within the literature. A particular area of contention in the literature is how student grades, their level of competitiveness and particular sources of pressure are related to plagiarism.

The International Journal for Educational Integrity is available online at:

http://www.ojs.unisa.edu.au/journals/index.php/IJEI/

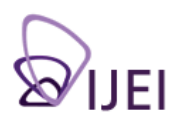


Plagiarism is a form of cheating, and the strongest motive for cheating by students may be the desire to obtain high grades (Bennett, 2005). Consistent with this, some authors claim that the dishonest pursuit of obtaining good marks could be due to the pressure students experience to prove their worth to themselves or to others (Davis, Grover, Becker, \& McGregor, 1992; Newstead, Franklyn-Stokes, \& Armstead, 1996). Research indicates that such pressures can lead to decisions to engage in various forms of academic dishonesty (McCabe, Treviño, \& Butterfield, 2001).

Understandably, engaging in plagiarism to optimise their performance is a means that some students may use to manage the pressures they feel to achieve good grades. Thus, there are reasons to believe that the grades students achieve, and self-imposed and other-imposed pressure to achieve grades, may be positively related to plagiarism.

According to Bennett (2005), the incentive to take 'short cuts' (i.e. plagiarise) in order to succeed is greater among people with a pronounced goal orientation (e.g. the goal of getting a good job). Therefore, competition for both obtaining high grades and acquiring jobs may also contribute to plagiarism, especially among students who have a dispositional tendency toward competitiveness. For example, there have been some reports of evidence demonstrating that individuals whose behavioural and emotional styles were characterised by the aggressive struggle to achieve more in less time (often in competition with other students) had a higher tendency to plagiarise than their classmates (Davis, Pierce, Yandell, \& Arnow, 1995). Moreover, pressure of competition within the job market may add to self-imposed and other-imposed demands to perform well (Harding, Carpenter, Finelli, \& Passow, 2004).

Financial pressures may also contribute to grade-related pressures to engage in plagiarism, if financial pressures necessitate students undertaking paid employment during their studies. Students who take paid employment to help finance their time at university have less time for study since increased hours dedicated to outside responsibilities may cause problems with time management (Devlin, James, \& Grigg, 2008; Larkham \& Manns, 2002; Maxwell, Curtis, \& Vardanega, 2008; Passow, Mayhew, Finelli, Harding, \& Carpenter, 2006). In short, as a consequence of time pressures created by students undertaking paid employment, they may be more inclined to take 'short cuts' or 'lazy' options to complete assessment tasks, where one of these options may be engaging in plagiarism.

Even financial support that may reduce students' need to take paid work may, in fact, have a bearing on plagiarism by creating other-imposed pressures to perform well. For example, studies suggest that individuals who receive extensive financial support from their families and/or who are under great parental pressure to succeed, might be especially fearful of failure and hence be more inclined to plagiarise (e.g. Diekhoff et al., 1996; Haines, Diekhoff, LaBeff, \& Clark, 1986). In a study by Passow et al. (2006), scholarship students were more likely to cheat on exams than students without scholarships. The authors proposed that scholarship students are under more financial pressure to maintain a minimum Grade Point Average (GPA) and that their pursuit of higher grades, and the added pressures of finances, can increase the incidence of cheating. Since scholarship students in their study tended to have higher grades than students without scholarships (Passow et al., 2006), this again suggests a potential connection between grades and plagiarism.

In contrast to the studies discussed so far, other studies have indicated that lower, rather than higher grades may be associated with plagiarism, and that those students who place more pressure on themselves to achieve high grades may avoid plagiarism. For example, a study by Haines et al. (1986), found that students with lower than average GPAs were more likely to plagiarise than their better-performing counterparts. Newstead et al. (1996) explain that higher achievers are more likely to be individuals who have learning goals, as opposed to lower achievers whose main goal is simply to get through their studies. They go on to argue that those individuals 
with learning goals are more likely to persist in challenging tasks and that it is reasonable to assume that these students will be less likely to resort to cheating as a way of coping with a demanding situation. Similarly, other research has found that students who have a conscientious personality are less likely to plagiarise (de Bruin \& Rudnick, 2007).

In summary, an examination of the literature on factors related to student plagiarism indicates mixed evidence in relation to pressure and grades achieved. Some studies and theories suggest that the pressures students experience (from themselves, others, career expectations, and working hours), and their level of achievement, are related to increased incidence of plagiarism, whereas other theories and evidence suggest the opposite. To make a contribution to the evidence in this area we measured pressures (work time, self-imposed, other-imposed, and competitiveness) and students' grades in a survey of student plagiarism. This survey also allowed a unique opportunity to examine historical trends in plagiarism, which is discussed next when we outline the current study.

\section{The current study}

In 2009 we collected data at the University of Western Sydney (UWS) using an anonymous survey of student plagiarism. The survey questionnaire was identical to that used five years earlier at UWS by Maxwell, Curtis, and Vardanega (2006), except that we added measures of factors related to plagiarism (specifically, pressures and student grades).

Because we used an identical questionnaire to that used by Maxwell et al. (2006, 2008) at the same university, we were able to examine historical changes in rates of plagiarism, understanding of plagiarism, and perceived seriousness of plagiarism. We should note that there is limited research that compares rates of student plagiarism over time (e.g. Diekhoff et al., 1996). As Park (2003) noted, "[l]ongitudinal...data on student cheating are thin on the ground" (p. 478). Therefore, the data provided by the present study that examined comparable student groups at the same institution five years apart makes a helpful and interesting contribution to the literature.

\section{Methodology}

\section{Participants and procedure}

In 2009 we administered a questionnaire to students that was designed to collect information on the extent to which they had engaged in plagiarism, their understanding of plagiarism, the extent to which they perceived plagiarism to be serious, and factors thought to be related to plagiarism. In this study we report two sets of analyses. The first set of analyses is the descriptive data analysis of rates of plagiarism, perceived seriousness of plagiarism, and understanding of plagiarism. In presenting the descriptive analyses we compare the results of the 2009 survey with a survey of plagiarism conducted with students in 2004 (Maxwell et al., 2006, 2008). The second set of analyses examine factors thought to be related to plagiarism that were only included in the 2009 survey.

The data from 2009 came from delivering the same survey instrument as was administered by Maxwell et al. $(2006,2008)$, to 120 students. The data from the 2004 survey came from the research of Maxwell et al., which initially contained 267 participants. In both 2004 and 2009, all students were drawn from UWS. In the 2009 data collection, students were primarily drawn from first-year and second-year business and arts units. By contrast, the 2004 data were collected from a broader range of year groups and disciplines. Both academic discipline and time spent at university are related to students' opportunities to plagiarise (Ledwith, Risquez, \& 
O'Dwyer, 2010). Thus, in order to have comparable samples for the 2009 and 2004 comparisons, analyses were limited to first-year and second-year business and arts students. Placing this restriction on the sample left 114 students in the 2009 group and 174 in the 2004 group. These groups had similar proportions of first-year and second-year students and similar proportions of business and arts students (see Table 1). The 2009 students $(M=22.15, S D=6.36)$ and 2004 students $(M=21.12$, $S D=4.77)$ did not differ significantly in age, $t(194)=1.47, p=0.14 .^{1}$

Table 1:

Percentage of first-year and second-year students and business and arts students by year of data collection

\begin{tabular}{lccc}
\hline Year level or Major & $\mathbf{2 0 0 9}$ & Year of Survey & $\mathbf{2 0 0 4}$ \\
& $\mathbf{\%}$ & $\mathbf{\%}$ \\
\hline First-year & 66.7 & 63.2 \\
Second-year & 33.3 & 36.8 \\
Business & 64.9 & 79.3 \\
Arts & 35.1 & 20.7 \\
\hline
\end{tabular}

Both the 2004 and 2009 surveys were administered in the second semester of the year in which the data were collected. This timing of data collection was thought to be necessary so that first-year students who participated in the research had had an opportunity to complete some study and assessments at university, and therefore they had the opportunity to both learn about and engage in plagiarism.

To maintain fidelity with the 2004 survey, data in 2009 were collected both online and via hardcopy surveys. Additionally, consistent with the 2004 survey, students who participated were offered the opportunity to enter a prize draw or receive partial course credit in a psychology unit (for first-year psychology students only) as an inducement for their participation.

\section{Survey instrument}

Table 2:

Types of plagiarism

\begin{tabular}{|c|c|}
\hline Type & Definition \\
\hline Sham Paraphrasing & $\begin{array}{l}\text { Material copied verbatim from text and source acknowledged in-line } \\
\text { but represented as paraphrased }\end{array}$ \\
\hline Illicit Paraphrasing & $\begin{array}{l}\text { Material paraphrased from text without in-line acknowledgement of } \\
\text { source }\end{array}$ \\
\hline Other Plagiarism & $\begin{array}{l}\text { Material copied from another student's assignment with the } \\
\text { knowledge of the other student }\end{array}$ \\
\hline Verbatim Copying & $\begin{array}{l}\text { Material copied verbatim from text without in-line acknowledgement } \\
\text { of the source }\end{array}$ \\
\hline Recycling & Same assignment submitted more than once for different courses \\
\hline Ghost Writing & Assignment written by third party and represented as own work \\
\hline Purloining & $\begin{array}{l}\text { Assignment copied from another student's assignment or other } \\
\text { person's papers without that person's knowledge }\end{array}$ \\
\hline
\end{tabular}

Note. From Walker, J. (1998). Student plagiarism in universities: What are we doing about it? Higher Education Research and Development, 17, 103. 
The survey instrument used in this research is presented in Appendix A of Maxwell et al. (2008). The survey presents seven vignettes that represent the seven categories of plagiarism described by Walker (1998) (see Table 2). Prevalence of plagiarism was indicated by students' response for each type of plagiarism concerning whether they have engaged in a similar action to that described in the vignette using a 5-point scale (1 $=$ never, $2=$ only once, $3=2-3$ times, $4=4-7$ times, $5=$ more than 7 times). Understanding of plagiarism is assessed by students indicating whether they consider the actions described in the vignette to be a form of cheating. Perceived seriousness of plagiarism was measured by students indicating the extent to which they considered the actions described in each vignette to be serious, using a 3-point scale $(1=$ not at all serious, 2 = moderately serious, 3 = very serious). Further details of this scale can be found in Maxwell et al. (2008).

We conducted some additional analysis on our full dataset to investigate the reliability of the questionnaire. The seven prevalence of plagiarism questions, taken together as an overall scale of prevalence of plagiarism, had a Cronbach's (1951) alpha internal consistency reliability of 0.69 , which is acceptable for a research measure with a small number of items. This suggests that these items measure a single concept of likelihood of plagiary. Similarly, the Cronbach's alpha was an acceptable 0.67 for the perceived seriousness of plagiarism items.

For the 2009 survey, five questions were added to the questionnaire to examine factors identified as being related to plagiarism. First, to measure student competitiveness the question: "How competitive do you consider yourself to be?" was added, using a 4-point response scale $(1=$ Not at all, $2=$ Little, $3=$ Moderately, or $4=$ Very). Second, to get an indication of what grades the students achieve, they were asked: "What grades do you usually get?" with the options of 'High Distinction', 'Distinction', 'Credit', or 'Pass'. To measure the students' self-imposed and other-imposed pressures to achieve high grades, two questions were added: "How much pressure do you put on yourself to achieve high grades?" and "How much pressure do others put on you to achieve high grades?". These two items had a 4-point response scale of 1 = 'None', 2 = 'Little', 3 = 'Moderate', or $4=$ 'Much'. Finally, students were asked to indicate the number of hours per week they spent in paid or voluntary employment.

\section{Results}

In this section we present the descriptive statistics for the prevalence of plagiarism, the perceived seriousness of plagiarism, and understanding of plagiarism. In presenting descriptive statistics we compare the data from the present study collected in 2009 with the 2004 data. After the descriptive data and historical comparisons, the analyses of factors related to plagiarism are presented.

\section{Data screening and statistical assumptions}

Before analyses were undertaken the data were screened for breaches of statistical assumptions such as normality, skew, kurtosis, and outliers. The data were sufficiently normally distributed, given the sample size, for the analyses that were undertaken to be conducted reliably.

\section{Prevalence of plagiarism}

Comparing the two testing times, there was a lower percentage of students who had engaged in any form of plagiarism at least once in the 2009 sample $(74.6 \%)$ as compared with the 2004 sample (80.5\%). This decline in the percentage of students who had ever engaged in any of the forms of plagiarism at least once was not significant chisquare $(1, N=288)=1.40, p=0.236$. However, comparing the frequency of plagiarism, based on the average rating for the seven scenarios on the 5-point scale of frequency of plagiarism, there was significantly less plagiarism among the 2009 sample $(M=1.42, S D$ $=0.47)$ than among the 2004 sample $(M=1.58, S D=0.57), t(271)=2.58, p=0.01, d=$ 0.31 . 
As a point of interest, although the percentage of students who had engaged in any of the forms of plagiarism is quite high, the average frequency was quite low. This means that although most students had engaged in plagiarism at least once they tended to have done so on only a few occasions.

Examining the different forms of plagiarism, as shown in Table 3, a lower percentage of students in 2009 compared with 2004 had ever engaged in five of the seven forms of plagiarism. In both 2009 and 2004 more than half of all students had engaged in sham paraphrasing at least once in their time at university.

Looking at the frequencies (as rated on the 5-point scale) six out of seven forms of plagiarism had declined in 2009 as compared with 2004. In addition, there was a significant drop in two types of plagiarism: illicit paraphrasing and other plagiarism. Illicit paraphrasing, which was the most frequent form of plagiarism among students in 2004 , fell to being the second most frequent form in 2009 . $^{2}$ Furthermore, there was close to a significant decline in verbatim copying. Two of the seven types of plagiarism that did not differ significantly between 2004 and 2009, ghost writing and purloining, had very low rates in both years.

Table 3:

Percentage of students who have ever engaged in each type of plagiarism and mean frequency (on the 5-point rating scale).

\begin{tabular}{|l|c|c|c|c|c|}
\hline & $\mathbf{2 0 0 9}$ & $\mathbf{2 0 0 4}$ & $\mathbf{2 0 0 9}$ & $\mathbf{2 0 0 4}$ & \\
\hline Type of Plagiarism & $\%$ & $\%$ & Mean & Mean & Significance $(p)$ \\
\hline Sham Paraphrasing & 50.9 & 54.0 & 2.01 & 2.16 & 0.327 \\
\hline Illicit Paraphrasing & 47.4 & 63.2 & 1.94 & 2.45 & $0.001^{*}$ \\
\hline Other Plagiarism & 8.8 & 16.7 & 1.13 & 1.28 & $0.032^{*}$ \\
\hline Verbatim Copying & 23.7 & 30.5 & 1.40 & 1.59 & 0.085 \\
\hline Recycling & 29.8 & 29.3 & 1.39 & 1.49 & 0.234 \\
\hline Ghost Writing & 3.5 & 1.1 & 1.06 & 1.03 & 0.364 \\
\hline Purloining & 2.6 & 6.3 & 1.04 & 1.08 & 0.169 \\
\hline
\end{tabular}

* = significance of differences between means for 2009 and 2004 at $p<0.05$ based on $t$-tests for independent samples.

\section{Understanding of plagiarism}

The survey presented seven different scenarios, each representing a form of plagiarism. Therefore, if a student indicated that they considered the scenario to be a type of cheating, this was scored as indicating that the student understood that the action described in the scenario was plagiarism. 
Table 4:

Percentage of students who understood that each type of plagiarism was a form of plagiarism.

\begin{tabular}{lccc}
\hline & \multicolumn{2}{c}{ Year of Survey } & \\
Type of Plagiarism & $\mathbf{2 0 0 9}$ & $\mathbf{2 0 0 4}$ & Significance \\
\hline Sham Paraphrasing & 58.8 & $\mathbf{\%}$ & $(\boldsymbol{p})$ \\
\hline Illicit Paraphrasing & 78.1 & 29.3 & $0.001^{*}$ \\
Other Plagiarism & 95.6 & 69.0 & 0.090 \\
Verbatim Copying & 94.7 & 86.2 & $0.009^{*}$ \\
Recycling & 28.1 & 95.4 & 0.797 \\
Ghost Writing & 91.2 & 16.1 & $0.014^{*}$ \\
Purloining & 99.1 & 71.8 & $0.001^{*}$ \\
\hline
\end{tabular}

${ }^{*}=$ significant differences between 2009 and 2004 at $p<0.05$ based on Chi-square test.

As shown in Table 4, there was an increase between 2004 and 2009 in students' understanding that various actions constitute cheating. A higher percentage of students in 2009 identified the actions described in the survey scenarios as cheating, for six out of the seven forms of plagiarism. Students in 2009 identified four forms of plagiarism (sham paraphrasing, other plagiarism, recycling, and ghost writing) as cheating, significantly more frequently than had students in 2004. Additionally, there was close to a significant increase from 2004 to 2009 in the percentage of students who understood illicit paraphrasing to be a form of cheating.

Verbatim copying and purloining were identified as cheating by the vast majority of students in both 2009 and 2004. There was no significant difference between the percentages of students in 2009 and 2004 who understood that verbatim copying and purloining are forms of cheating. This lack of significant change can be considered the result of a ceiling effect, where scores that are already near the top of the possible range of scores (in this case approaching 100\%) cannot increase significantly above that point (Grimm, 1993).

\section{Perceived seriousness of plagiarism}

Table 5:

Average seriousness ratings for each type of plagiarism by year of data collection

\begin{tabular}{lccc}
\hline & $\mathbf{2 0 0 9}$ & Year of Survey & \\
Type of Plagiarism & Mean & $\mathbf{2 0 0 4}$ & Significance \\
& 1.96 & 1.59 & $(\boldsymbol{p})$ \\
\hline Sham Paraphrasing & 2.11 & 1.93 & $0.001^{*}$ \\
Illicit Paraphrasing & 2.84 & 2.57 & $0.023^{*}$ \\
Other Plagiarism & 2.78 & 2.61 & $0.001^{*}$ \\
Verbatim Copying & 1.68 & 1.47 & $0.006^{*}$ \\
Recycling & 2.86 & 2.52 & $0.013^{*}$ \\
Ghost Writing & 2.94 & 2.90 & $0.001^{*}$ \\
Purloining & & & 0.21 \\
\hline
\end{tabular}

* $=$ significance of differences between means for 2009 and 2004 at $p<0.05$ based on $t$ -tests for independent-samples. 
Comparing the perceived seriousness of plagiarism, based on the average rating on the 3-point scale for the seven scenarios, the 2009 students $(M=2.45, S D=0.28)$ considered plagiarism to be more serious than the 2004 students $(M=2.23, S D=$ $0.34), t(273)=6.15, p<0.001, d=0.74$.

As can be seen in Table 5, all seven types of plagiarism were perceived as more serious by students in 2009 than by students in 2004. Six of the seven types of plagiarism were perceived as significantly more serious by participants in 2009 as compared with 2004. The lack of a significant difference for purloining can be attributed to a ceiling effect. In both years, purloining was evaluated, on average, nearly at the maximum of the 3-point seriousness scale. Thus, there was little scope for the average rating of purloining to increase any further.

\section{Factors related to plagiarism}

Correlations were calculated, for the 2009 sample, to examine the extent to which the factors we measured were related to overall prevalence of plagiarism. Three factors were significantly correlated with prevalence of plagiarism: pressure students place on themselves to achieve high grades $(r=-0.201, p=0.032)$, students' competitiveness $(r=-0.188, p=0.045)$, and perceived seriousness of plagiarism $(r=-0.329, p<0.001)$. The following factors were not significantly correlated with prevalence of plagiarism: average hours of employment, grades usually achieved by students, and pressure from others for students to perform well. Interestingly, the three factors that were related to plagiarism showed a negative correlation. This indicates that students who place pressure on themselves, are more competitive, and who consider plagiarism to be more serious are less likely to engage in plagiarism.

Two of the significant predictors of plagiarism, perceived seriousness and pressure students place on themselves, were significantly correlated with each other $(r=0.254$, $p=0.006$ ). Since these two predictors of plagiarism correlated with each other, it was likely that they were not, mathematically speaking, unique predictors of incidence of plagiarism. One possibility is that students who place pressure on themselves to do well consider plagiarism to be a more serious problem. They may, for example, see plagiarism as serious because it would reduce their chances of doing well if they were caught engaging in plagiarism. Therefore, we tested the possibility that perceived seriousness of plagiarism mediated the relationship between the extent to which students place pressure on themselves and prevalence of plagiarism. This analysis used the regression method for determining mediation described by Baron and Kenny (1986). As shown in Figure 1, the extent to which students place pressure on themselves to produce good grades positively predicted the extent to which they perceived plagiarism to be serious, which subsequently negatively predicted the extent to which they engage in plagiarism. In other words, students who placed pressure on themselves to do well consider plagiarism to be more serious and consequently engage in less plagiarism. Additionally, when perceived seriousness is accounted for, pressure students place on themselves did not directly predict prevalence of plagiarism significantly, indicating that this is a mediated relationship.

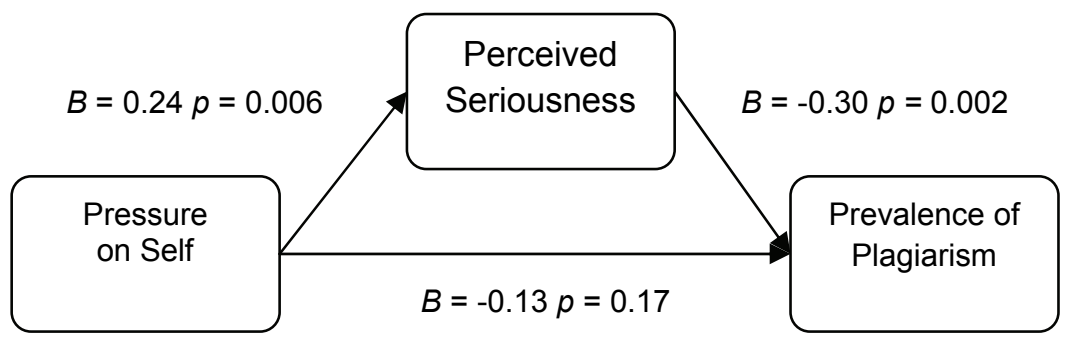

Figure 1: Perceived seriousness of plagiarism mediated the relationship between pressure students place on themselves and prevalence of plagiarism. 
Although grades that students usually achieved were not significantly correlated with plagiarism, we conducted an additional analysis of the relationship between grades and prevalence of plagiarism based on predictions outlined in the literature. Previous studies, although sometimes using correlational analyses, suggested that differences may lie between students who achieve higher vs. lower grades (e.g. Haines et al., 1986; Passow et al., 2006). Thus, these studies' conclusions suggested that grades may be of interest as a grouping variable rather than as a continuous variable. We grouped students with usual grades of High Distinction or Distinction into a 'high grades' group $(N=54)$ and students with usual grades of Credit or Pass into a 'low grades' group $(N=66)$. Students in the high grades group had a significantly lower prevalence of plagiarism $(M=1.32, S D=0.36)$ than students in the low grades group $(M=1.50, S D=0.52), t(118)=2.11, p=0.037, d=0.39$.

\section{Discussion}

\section{Factors related to plagiarism}

As outlined earlier in this paper, there is some conflict within the literature as to whether pressure (from various sources) to achieve high grades and the grades that students achieve are related to prevalence of plagiarism (Davis et al., 1995; Haines et al., 1986). When measuring particular sources of pressure, we found that students' competitiveness and the pressure they put on themselves to do well were negatively related to prevalence of plagiarism. Students with lower grades plagiarised more than students with higher grades. However, pressure from others to do well and working hours were unrelated to their prevalence of plagiarism. In addition, we found that the extent to which students perceive plagiarism to be a serious problem is negatively correlated with prevalence of plagiarism, which is consistent with other recent findings (e.g. Maxwell et al., 2008; Stephens, Romakin, \& Yukhymenko, 2010). Additionally, the forms of plagiarism that were significantly lower between 2009 and 2004 were rated as significantly more serious by students in 2009 as compared with the ratings of students in 2004. This parallel of changes in results over time for perceived seriousness of plagiarism and prevalence of plagiarism is consistent with the correlation between perceived seriousness and prevalence of plagiarism.

The finding that students with lower grades tended to engage in more plagiarism is inconsistent with the findings of Passow et al. (2006). It is notable that the high achieving students in Passow et al.'s research were scholarship holders at American universities who experienced pressure to achieve high grades in order to keep their scholarships. Student scholarships are rare in Australia, where the present research was conducted. Although we did not ask participants in our study whether they held scholarships, it is likely that few, if any, did. Thus, it is unlikely that the high achieving students in our study had the same financial pressure of retaining scholarships that may have motivated plagiarism as the students in Passow et al.'s research.

The findings of the present study in relation to factors relating to plagiarism, because of the correlational methodology, leave open the question of causality. That is, although we found that self-imposed pressure to perform well is related to reduced plagiarism, this does not immediately tell us why self-imposed pressure to perform well is related to a reduced incidence of plagiarism. However, we can speculate as to why students who are competitive and/or who place pressure on themselves to perform well may eschew plagiarism. People who are competitive and place pressure on themselves to perform well tend to have conscientious personalities (ChamorroPremuzic \& Furnham, 2010). Thus, the current findings appear to be consistent with the evidence that conscientiousness is related to lower levels of plagiarism (de Bruin \& Rudnick, 2007), and it may be that students' conscientiousness underlies our results. 
The mediational analysis of our results suggests a possible mechanism by which selfimposed pressure reduces incidence of plagiarism: perception of plagiarism as a serious problem. Extending the possible chain of causality, it may be that conscientious students put pressure on themselves to do well, that this pressure leads them to be more concerned about the ramifications of plagiarism and hence they avoid plagiarism as a consequence. Further research is required to investigate this possibility.

Students who put pressure on themselves to do well may perceive plagiarism to be more serious for a number of reasons. As we suggested earlier, it may be that they see plagiarism as a possible impediment to good performance if they are caught and penalised. Consistent with this explanation, Diekhoff et al. (1996) found that fear of punishment strongly deterred cheating. Alternatively, they may feel that plagiarism is serious when engaged in by others because it gives other students an unfair advantage. Again, however, more research is needed to investigate the reasons for the connection between self-imposed pressure and perceived seriousness of plagiarism. In sum, the present study adds to existing data on possible causes of plagiarism and suggests some future avenues of investigation in this regard.

\section{Longitudinal changes in plagiarism at UWS}

The comparison of 2009 with 2004 data showed significant changes in understanding of plagiarism, perceived seriousness of plagiarism, and prevalence of plagiarism. In general, the 2009 students plagiarised less, perceived plagiarism to be more serious, and were more likely to understand that various activities constitute plagiarism, as compared with the students surveyed five years earlier. As a global trend, these results are very encouraging to academics who are concerned with educational integrity. More encouraging is that these data represent a reversal of the trend towards increased plagiarism noted in other recent longitudinal studies (Mastin, Peszka, \& Lilly, 2009; Park, 2003).

There are a multitude of possible reasons for the changes observed in rates, understanding, and perceived seriousness of plagiarism among UWS students between 2004 and 2009. However, for the benefit of future researchers who may wish to investigate causes of change, we have identified three changes that occurred at UWS between 2004 and 2009 that are likely candidates for producing the changes observed in plagiarism: assessment policy, teaching methods, and the adoption of the Turnitin text-matching software.

In 2008 UWS began the phased introduction of a university-wide criteria and standards-based assessment policy. It has been argued that providing students with clear assessment criteria may reduce plagiarism (Devlin, 2006), although this contention is not universally accepted (see Norton, 2004). An early step in this policy was to supply all academic staff with a guide to educational assessment that principally focused on developing criteria and standards, but also included advice on reducing plagiarism (Armstrong, Chan, Malfroy, Thomson, \& Hendry, 2008; Thomson $\&$ Curtis, 2009). There is no data yet on the extent to which UWS academics followed the plagiarism-reduction advice provided to them. However, there is some evidence that UWS academics have taken up the policy in its early stages of implementation by setting criteria and standards for assessments (Thomson \& Curtis, 2009).

In 2007, UWS introduced an initial trial of the text-matching software Turnitin, with a wider up-take of the software in 2008 and 2009. Numerous studies suggest that Turnitin can contribute to a reduction in plagiarism rates (e.g. Davis \& Carroll, 2009).

Between 2004 and 2009 specific initiatives to improve understanding of referencing and plagiarism were built into large first-year level units in business and psychology. In business, a specific unit on academic skills such as referencing was made 
compulsory for all first-year students. In psychology, which was the major course of many of the arts students in both 2004 and 2009, competency-based referencing and plagiarism training was included in the large introductory psychology unit from 2005 (see http://tdu.uws.edu.au//qilt/elearning/exemplar_psychology/ Exemplar Psychology.htm).

As stated, although the changes to assessment policy, teaching practices, and the use of Turnitin are likely candidates for the changes observed between 2004 and 2009, we are unable to make definitive statements about their impact. Future longitudinal comparison of student plagiarism should attempt to measure the impact of variables that have the potential to cause historical changes in plagiarism rates.

\section{Conclusion and implications}

In analysing factors related to plagiarism, we found evidence supporting the assertion that students who place pressure on themselves to do well will plagiarise less. This finding, however, should be tempered by the fact that the correlation was quite small and was explained by these students' increased tendency to perceive plagiarism to be serious. In addition, perceived seriousness of plagiarism was the strongest predictor of prevalence of plagiarism. Thus, from a practical point of view, the best advice we can give to educators, based on our data, is that it may be beneficial to persuade students of the seriousness of plagiarism as an issue of integrity in higher education in order to reduce the prevalence of plagiarism.

The examination in prevalence, understanding, and perceived seriousness of plagiarism at UWS between 2004 and 2009 suggested some promising signs of improvement. Prevalence of plagiarism had fallen in total, but this was limited to several specific types of plagiarism. Understanding of plagiarism and perception of it as a serious problem increased over the five years; these results applied to most of the different types of plagiarism identified by Walker (1998), particularly those without a high level of recognition in the 2004 survey. The results of our five-year follow-up survey provide some grounds for optimism as they buck the previously-reported trend of increasing plagiarism in tertiary education institutions. These results suggest that reductions in plagiarism are possible, even in a mass higher education environment. However, further research is needed to examine the possible causes of changes observed between 2004 and 2009. In particular, it may be especially beneficial for future researchers to conduct investigations similar to the current study at different educational institutions, in order to examine plagiarism trends that occur at an institution that is different to UWS.

\section{Endnotes}

1. The two groups had unequal variances in their distributions of age and this $t$-test result is adjusted to compensate, hence the degrees of freedom are lower than in other analyses reported in this paper.

2. The prevalence of plagiarism data were moderately positively skewed. Although $t$ tests are robust with skewed data, particularly with large sample sizes as we had in this study, we conducted supplementary analyses with the nonparametric Mann-Whitney $U$ test. Consistent with the $t$-test results these tests showed that the 2009 and 2004 groups differed significantly in prevalence of illicit paraphrasing, prevalence of other plagiarism and total prevalence of plagiarism. 


\section{References}

Armstrong, S., Chan, S., Malfroy, J., Thomson, R., \& Hendry, G. (2008). Assessment guide: Implementing criteria and standards-based assessment. Penrith: University of Western Sydney.

Bennett, R. (2005). Factors associated with student plagiarism in a post-1992 university. Assessment \& Evaluation in Higher Education, 30, 137-162.

Baron, R. M., \& Kenny, D. A. (1986). The moderator-mediator variable distinction in social psychological research: Conceptual, strategic, and statistical considerations. Journal of Personality and Social Psychology, 51, 1173-1182.

Chamorro-Premuzic, T., \& Furnham, A. (2010). The psychology of personnel selection. Cambridge: Cambridge University Press.

Cronbach, L. J. (1951). Coefficient alpha and the internal structure of tests. Psychometrika, 16, 297-334.

Davis, M., \& Carroll, J. (2009). Formative feedback within plagiarism education: Is there a role for text-matching software? International Journal for Educational Integrity, 5, 58-70.

Davis, S., Grover, C., Becker, A., \& McGregor, L. (1992). Academic dishonesty: Prevalence, determinants, techniques and punishments. Teaching of Psychology, 19, 16-20.

Davis, S., Pierce, M., Yandell, L., \& Arnow, P. (1995). Cheating in college and the Type A personality. College Student Journal, 29, 493-497.

de Bruin, G. P., \& Rudnick, H. (2007). Examining the cheats: The role of conscientiousness and excitement seeking in academic dishonesty. South African Journal of Psychology, 37, 153-164.

Diekhoff, G. M., LaBeff, E. E., Clark, R. E., Williams, L. E., Francis, B., \& Haines, V. J. (1996). College cheating: Ten years later. Research in Higher Education, 37, 487-502.

Devlin, M. (2006). Policy, preparation, and prevention: Proactive minimization of student plagiarism. Journal of Higher Education Policy and Management, 28, 45-58.

Devlin, M., James, R., \& Grigg, G. (2008). Studying and working: A national survey of student finances and student engagement. Tertiary Education and Management, 14, 111-122.

Grimm, L. G. (1993). Statistical applications for the behavioral sciences. New York: Wiley.

Haines, V. J., Diekhoff, G. M., LaBeff, E. E., \& Clark, R. E. (1986). College cheating: Immaturity, lack of commitment and the neutralising attitude. Research in Higher Education, 25, 342-354.

Harding, T. S., Carpenter, D. D., Finelli, C. J., \& Passow, H. J. (2004). Does academic dishonesty relate to unethical behavior in professional practice? An exploratory study. Science and Engineering Ethics, 10, 311-324.

Larkham, P. J., \& Manns, S. (2002). Plagiarism and its treatment in higher education. Journal of Further \& Higher Education, 26, 339-349.

Landau, J. D., Druen, P. B., \& Arcuri, J. A. (2002). Methods for helping students avoid plagiarism. Teaching of Psychology, 29, 112-115.

Ledwith, A., Risquez, A., \& O'Dwyer, M. (2010). The role of the internet in academic honesty: a comparison of engineering and business students. Paper presented to the $3^{\text {rd }}$ International Symposium for Engineering Education, Cork, Ireland.

Mastin, D. F., Peszka, J., \& Lilly, D. R. (2009). Online academic integrity. Teaching of Psychology, 36, 174-178.

Maxwell, A. J., Curtis, G. J., \& Vardanega, L. (2006). Plagiarism among local and Asian students in Australia. Guidance and Counselling, 21, 210-215.

Maxwell, A. J., Curtis, G. J., \& Vardanega, L. (2008). Does culture influence understanding and perceived seriousness of plagiarism? International Journal for Educational Integrity, 4, 25-40. 
McCabe, D. L., Treviño, L. K., \& Butterfield, K. D. (2001). Cheating in academic institutions: A decade of research. Ethics and Behavior, 11, 219-232.

Newstead, S. E., Franklyn-Stokes, A., \& Armstead, P. (1996). Individual differences in student cheating. Journal of Educational Psychology, 88, 229-241.

Norton, L. (2004). Using assessment criteria as learning criteria: A case study in psychology. Assessment \& Evaluation in Higher Education, 29, 687-702.

Park, C. (2003). In other (people's) words: Plagiarism by university students literature and lessons. Assessment and Evaluation in Higher Education, 28, 471-488.

Passow, H. J., Mayhew, M. J., Finelli, C. J. Harding, T. S., \& Carpenter, D. D. (2006). Factors influencing engineering students' decisions to cheat by type of assessment. Research in Higher Education, 47, 643-684.

Stephens, J. M., Romakin, V., \& Yukhymenko, M. (2010). Academic motivation and misconduct in two cultures: A comparative analysis of US and Ukrainian undergraduates. International Journal for Educational Integrity, 6(1), 47-60.

Thomson, R., \& Curtis, G. (2009). An institutional approach to standards-based assessment: Evaluating early-stage implementation. Poster presented to the Australian Technology Network Assessment Conference, Melbourne, Australia.

Walker, J. (1998). Student plagiarism in universities: What are we doing about it? Higher Education Research and Development, 17, 103.

Zobel, J., \& Hamilton, M. (2002). Managing student plagiarism in large academic departments. Australian Universities Review, 45, 23-30.

\section{Acknowledgements}

The authors wish to thank Amanda Maxwell for allowing us access to her dataset for additional analysis, and Dr Nikola Balnave for her support of our efforts to collect data from business students. We would also like to thank the editor and anonymous reviewers for their helpful feedback on this paper.

\section{About the authors}

Guy Curtis is a Senior Lecturer in the School of Psychology at the Murdoch University, who completed a PhD at the University of Western Australia. He was previously employed at the University of Western Sydney when the data presented in this paper were collected. He has published across a range of topics in psychology as well as previous studies on student plagiarism.

Razma Popal is a registered psychologist working in both private practice and for the New South Wales, Sydney West Area Health Service. She completed a Master of Psychology (Educational and Developmental) at the University of Western Sydney. This study draws on some of the data collected in her Master of Psychology research thesis. 